\title{
Revistas dos Programas de Pós- Graduação em Comunicação registram a pesquisa sobre rádio
}

\section{Doris Fagundes Haussen}

Doutora; Pontifícia Universidade Católica do Rio Grande do Sul

dorisfah@pucrs.br

\section{Resumo}

O texto apresenta um panorama dos artigos com a temática sobre o rádio, publicados em revistas da área da Comunicação, classificadas com Qualis A2 e B1 pela CAPES, no período 20022012. Aborda-se, especificamente, os periódicos dos três Programas de Pós-Graduação em Comunicação (stricto sensu) mais antigos do Rio Grande do Sul: PUCRS, UFRGS e UNISINOS. Pretendeu-se, assim, ter uma visão mais aprofundada do espaço ocupado pelo rádio nas publicações científicas da área, além de verificar os conteúdos mais abordados nessa produção, os autores que mais produziram e as referências mais utilizadas. Para a escolha dos textos, foram selecionados aqueles em que o título e o resumo indicassem a vinculação com o tema "rádio". Foram identificados 20 artigos sobre rádio e os conteúdos mais abordados foram os relativos a estudos de recepção/mediações e a narrativas radiofônicas.

\section{Palavras-chave}

Rádio. Revistas de Comunicação. Rio Grande do Sul.

\section{Introdução}

As revistas científicas constituem-se em arquivos importantes da produção acumulada pelos pesquisadores da área, fornecendo material relevante para o desenvolvimento de outros trabalhos, além de consultas em geral. Neste sentido, este artigo traz um panorama da produção sobre o rádio no Rio Grande do Sul, publicada nos periódicos classificados como níveis A2 e B1 pela Coordenadoria de Aperfeiçoamento de Pessoal de Nível Superior - 
CAPES, da área da Comunicação, entre 2002 e 2012¹. Os periódicos analisados pertencem aos Programas de Pós-Graduação em Comunicação (stricto sensu) mais antigos do Estado: PUCRS (1994), UNISINOS (1994) e UFRGS (1995), todos com 20 anos, sendo que o da UFRGS comemora a data neste ano de 2015. Assim, para este estudo foram analisadas as revistas que se enquadram na avaliação da CAPES: Revista Famecos. Mídia, cultura e tecnologia (PUCRS, A2), Sessões do Imaginário (PUCRS, B1), Intexto e Em Questão (UFRGS, B1) e Fronteiras. Estudos midiáticos (UNISINOS, B1). No total, foram identificados 20 artigos, nos cinco periódicos.

\section{0 estudo anterior e o estado da arte}

Este artigo faz parte de uma pesquisa mais ampla em desenvolvimento pela autora ${ }^{2} \mathrm{e}$ que dá prosseguimento a outra, anterior, denominada: "A produção científica sobre o rádio no Brasil: livros, artigos, teses e dissertações (1991-2001)", finalizada em 2003, na qual foi feito um amplo levantamento da produção daquele período. Dos resultados constam dados quantitativos sobre o tema, prevalência de conteúdos e a inserção dentro do campo da Comunicação (HAUSSEN, 2004).

A revisão efetuada para a pesquisa indicou, naquele momento, a existência de um levantamento sobre obras publicadas até 1990, realizado pela pesquisadora Sonia Virginia Moreira que resultou no livro O Rádio no Brasil (1991; 2001, 2. ed.). A mesma autora, em conjunto com Nélia Del Bianco, publicou, ainda, um artigo intitulado A pesquisa sobre o rádio no Brasil nos anos oitenta e noventa (LOPES, 1999) em que identificou 21 títulos sobre o veículo (1990-1998). Um levantamento inicial sobre a produção do Grupo de Pesquisa Rádio e Mídia Sonora, da Intercom, foi realizado por Del Bianco e Zuculoto (1996) e apresentado em CD com o título Memória do GT Rádio da Intercom: seis anos de pesquisa em defesa do rádio (1991-1996). Atualizando-se estes dados verificou-se que, em 2005, Sonia Virginia Moreira publicou Pesquisa de rádio no Brasil: a contribuição da Intercom (1997-2004) e em 2008, o artigo Rádio, em que faz um minucioso levantamento da publicação bibliográfica sobre o tema. Neste último, a autora refere-se a "125 textos, a maioria livros, mas também capítulos e artigos em revistas científicas" (MEL0, 2008, p. 129). No mesmo ano, Klöckner (2008) apresentou levantamento sobre teses e dissertações defendidas por autores gaú-

\footnotetext{
${ }^{1} 0$ período 2002-2012 foi selecionado para dar continuidade a pesquisa anterior da autora que abordou o período 1991-2001. ${ }^{2}$ A pesquisa atual intitula-se "A pesquisa sobre rádio no Brasil: artigos, teses e dissertações. Conteúdos e metodologias" e é desenvolvida com Bolsa PQ/CNPq,, contando com a colaboração da bolsista de Iniciação Científica CNPq/PUCRS, Niágara Reynaldo Braga.
} 
chos, no 6ํㅡㄹ Encontro Nacional da Rede Alcar, realizado na Universidade Federal Fluminense. Por outro lado, Luiz Artur Ferraretto publicou, em 2010, o texto sobre rádio e convergência digital em que também se refere a esta produção. Na mesma linha, Prata et al., 2011), analisaram os estudos sobre rádio nas instituições de ensino superior de Belo Horizonte.

No Congresso da Intercom 2011, esta autora proferiu palestra no GP Rádio e Mídia Sonora em que atualizava, até 2010, os dados quantitativos em relação às teses $e$ dissertações, verificando que 123 tinham sido apresentadas nos PPG em Comunicação brasileiros, sendo 30 teses e 93 dissertações (no período 1991-2001 tinham sido 106, das quais 90 dissertações e 16 teses). "Somando-se ao período anterior, observa-se que entre 1991 e 2010 foram defendidas 229 teses e dissertações relativas ao rádio nos PPG em Comunicação brasileiros" (HAUSSEN, 2011). Sobre os estudos mais recentes pode-se citar o de Lopez e Mustafá (2012), sobre as teses de doutorado defendidas nos Programas de PósGraduação, e o de Prata, Mustafá e Pessoa (2014), que aborda os pesquisadores de rádio no Brasil.

\section{Textos e autores}

Tendo em vista este panorama, o artigo produzido para a revista Intexto apresenta um recorte da pesquisa em desenvolvimento pela autora, e dedica-se a verificar a temática, os autores e as referências bibliográficas mais utilizadas nas cinco revistas dos três PPGs selecionados para a análise. Assim, apresentam-se, a seguir, os títulos, autores e resumos identificados nas revistas, no período 2002-2012:

A revista Intexto conta com quatro artigos no período analisado:

a) O "maior espetáculo da terra": O futebol e sua capacidade de transgredir os níveis de cultura de massa (2012), de Humberto Ivan Keske (Dr., PUCRS), Cleber Cristiano Prodanov (FFLCH/USP) e Vinícius Moser (Mestrando, FEEVALE)³. 0 artigo analisa de que forma os meios de comunicação, especialmente rádio, televisão e internet, reforçam o futebol e dão visibilidade nacional e internacional a esse esporte, dentro dos diferentes níveis de cultura propostos por Umberto Eco (2004). 0 texto também mostra de que maneira o futebol estabelece uma relação dialógica e contextual entre os diferentes níveis da cultura, sendo capaz de transgredi-los, reestruturando-os em uma nova proposta;

\footnotetext{
${ }^{3}$ Conserva-se, neste artigo, as instituições de origem dos autores publicadas nos artigos, embora muitos deles pertençam, na atualidade, a outras instituições.
} 
b) A Expressão Radiofônica de Uma Cartografia Sonora: estudo da série Porto Alegre, paisagens sonoras (2007), de Cida Golin (Dr., PUCRS). 0 artigo discute a relação entre o rádio e a cidade a partir da análise do projeto "Porto Alegre: paisagens sonoras", desenvolvido entre 2005 e 2007, pelos alunos do Curso de Jornalismo na Faculdade de Biblioteconomia e Comunicação da UFRGS. Segundo os autores, a série de documentários e reportagens propôs outros referenciais de percepção e imaginação da cidade para além da palavra e da voz, subvertendo em parte o que se costuma apreender do espaço urbano no rádio. A experiência pedagógica interpreta o espaço urbano por meio da recolha e da montagem de seus sons e discute os limites e as possibilidades do radiojornalismo na concretização desta iniciativa;

c) No ar, a comunidade: um estudo de recepção a partir das rádios comunitárias de Santa Maria (2010), de Carlos Sanchotene (Mestrando, UNISINOS), Rosana Zucoloto - (Doutoranda, UNIFRA); Juliano Pires (Graduando, UNIFRA). 0 trabalho busca compreender o processo de recepção dos conteúdos transmitidos pelas rádios comunitárias Caraí FM e Comnorte e a sua representatividade junto aos ouvintes das regiões sul e norte de Santa Maria - RS. Com base nos estudos sobre comunicação, recepção e rádios comunitárias, foi utilizada a metodologia dos grupos focais para a discussão e análise da recepção das programações, suas formas de produção e como se estabelece a relação entre os moradores das comunidades e as emissoras. Entre os resultados foi verificada uma participação limitada por parte dos ouvintes;

d) Produção negociada de políticas de Radiodifusão Pública: A participação da sociedade no Conselho Deliberativo da Fundação Cultural Piratini (2009), de Edna Miola (Doutoranda, UFMG). 0 artigo reflete sobre como as emissoras públicas podem contribuir na produção de políticas para o setor. Analisa-se a experiência do Conselho Deliberativo da Fundação Cultural Piratini (RS). Como operadores analítico-metodológicos, são acionados determinados pressupostos da idéia de deliberação pública, a fim de se examinar características discursivas do Conselho. A análise evidenciou que a criação do colegiado aprofundou o grau de discutibilidade e de accountability das políticas estaduais de radiodifusão. A autora conclui que a capacidade propositiva do órgão, porém, foi limitada pela situação assimétrica de poder em que o Conselho se encontra em relação ao Governo. 
A Revista Em Questão apresenta dois artigos:

a) Rádios Universitárias Públicas: compromisso com a sociedade e com a informação (2003), de Sandra de Deus (UFRGS). A autora apresenta uma reflexão sobre a função, os acertos e a situação das rádios universitárias pertencentes às Instituições Federais de Ensino Superior (IFES), que passam a ser denominadas de rádios universitárias públicas. Aponta para o fato de que, entre as 52 universidades, fundações e faculdades federais, 18 possuem emissoras de rádios AM ou FM, sendo que uma Universidade possui duas emissoras totalizando 19 rádios universitárias públicas devido a sua vinculação com estas instituições. 0 artigo considera o papel decisivo destas rádios para a construção de uma nova universidade pública;

b) O Rádio como monitor do trânsito, termômetro e cronômetro da cidade (2010), de Cida Golin (UFRGS). 0 artigo apresenta os resultados do segmento radiofônico da pesquisa "Porto Alegre Imaginada: representações dos cidadãos sobre a cidade", projeto coletivo desenvolvido entre 2007 e 2009 na Fabico/UFRGS. A partir da metodologia estabelecida por Silva (2004), conforme a autora, foram analisadas 24 horas e dez minutos de seis programas de emissora locais, considerando os estratos analíticos: sonoro, fônico-linguístico, temporal e objetos apresentados na narração. Constatou-se que Porto Alegre, nas narrativas radiofônicas escolhidas, constitui uma cidade descentrada. Conforme Golin, na sua condição ubíqua de serviço e companhia, a mídia radiofônica atua como guia da mobilidade física do sujeito, cumprindo a função de termômetro e cronômetro da cidade. Desvela a condição de metrópole, mas também o tempo lento do bairro.

A Revista Fronteiras: Estudos Midiáticos apresenta três artigos:

a) Identidade política e programação das rádios públicas: estudo comparativo de quatro emissoras federais (2009), de Silvia Mugnatto Nogueira (Doutoranda IESP/UERJ), Antonio Teixeira de Barros (UNB) e Cristiane Brum Bernardes (Dr. UERJ, Docente do Mestrado Profissional em Poder Legislativo da Câmara dos Deputados). Os autores partem da questão: A programação de uma emissora de rádio institucional reflete sua identidade política? A partir desta pergunta inicial, o artigo analisa a grade de programação das principais emissoras de rádio (FM) 
das instituições que representam os Três Poderes: Rádio Nacional FM, Rádio Senado, Rádio Câmara e Rádio Justiça. 0 objetivo é avaliar se os gêneros de programação predominantes em cada emissora estão em consonância com sua identidade política/institucional. Para tanto, a comparação é pautada nos elementos: os objetivos institucionais de cada emissora; o modo como cada uma se autodefine (pública, estatal, institucional); e a percepção de seus gestores. 0 pressuposto que orienta o estudo é o de que as emissoras institucionais de rádio criadas na década de1990 são herdeiras da tradição do rádio educativo criado na década de 1960. Conclui que tal herança persiste na atualidade, mas com uma nova abordagem, cujo foco é a educação para a democracia e a cidadania. Mas permanece o modelo tradicional de gestão, baseado no poder unilateral do Estado de decidir o que o cidadão deve saber;

b) O popular e a leitura radiofônica: um estudo de recepção entre jovens camponeses (2008), de Veneza Mayora Ronsini e Alexania Rossato (UFSM). 0 texto tem o objetivo de compreender como a identidade dos jovens participantes do Movimento dos Atingidos por Barragens (MAB) é constituída através do processo de recepção do rádio. Exploram-se as interpretações do receptor em relação ao discurso do rádio com base nas categorias de mediação da cotidianidade e do movimento social, inspiradas nos Estudos Latino-Americanos de Recepção e na abordagem etnográfica. Em sentido amplo, está em questão o processo hegemônico: o movimento social define seus interesses contra as emissoras de rádio e as empresas envolvidas na construção da Usina Hidrelétrica Barra Grande;

c) Rádio musical e concessão pública: uma reflexão a partir de duas emissoras "roqueiras", (2008), de Heitor da Luz (UNIFOA). 0 artigo focaliza a relação entre a configuração simbólica de duas emissoras que atuaram como "rádios rock" no Rio de Janeiro, em dois momentos distintos, e as características de suas inserções como agentes do mercado musical. Partindo da mesma rotulação e buscando atingir um público similar, a Fluminense FM, nos anos oitenta, e a Rádio Cidade, no início deste século, estabeleceram dois modelos de atuação nos mercados radiofônico e musical, que seriam decisivos para o nível de autonomia que cada uma obteria em relação aos outros agentes. Analisando algumas das especificidades dos modelos e das estratégias das emissoras, o trabalho propõe, ainda, 
uma discussão que articula a rádio FM musical aos processos de concessão pública dos meios de comunicação radiodifusores.

A Revista Famecos apresenta oito artigos:

a) Rádio comunitária na Internet: empoderamento social das tecnologias (2006), de Cicilia M. K. Peruzzo (UMESP). Em seu resumo a autora diz que o artigo estuda a inserção das rádios comunitárias na internet. Objetiva situar o cenário em que essas emissoras atuam no Brasil, compreender as formas de ocupação de espaço na rede pelo rádio, averiguar as tendências de programação, características de cunho comunitário presentes, formas de participação popular viabilizadas, e se há evidências de sua contribuição no exercício da cidadania.

b) A "geração podcasting" e os novos usos do rádio na sociedade do espetáculo e do entretenimento (2008), de Micael Herschmann (UFRJ) e Marcelo Kischinhevsky (PUC-RIO). Segundo os autores, a proposta foi repensar a importância da espetacularização e da alta visibilidade como fatores que permitiriam aos atores sociais "negociar" sentidos e significados na sociedade contemporânea. Consideram, assim, as apropriações das novas tecnologias um estudo de caso que permite avaliar as possibilidades de construção de linhas de fuga na sociedade atual, marcada por uma forte presença dos media e do entretenimento. Analisaram, também, o novo nicho de produção e consumo midiático viabilizado pela convergência tecnológica - especificamente o podcasting, modalidade de rádio sob demanda -, repensando a atuação dos usuários no estabelecimento de formas inovadoras de sociabilidade e mediação socioculturais.

c) O Universo Radiofônico de Ilhéus (BA): tênues fronteiras entre radialismo e políti$c a$, (2009), de Silvia Garcia Nogueira (UFRJ). A autora parte de um panorama sobre os meios de comunicação em Ilhéus (Sul da Bahia) e do mundo político municipal, analisando as estreitas relações estabelecidas entre ambos. A perspectiva adotada considera que entre a dinâmica cotidiana da vida política e as atividades diárias dos meios de comunicação há o estabelecimento de uma intimidade muito próxima, e que abordar o universo do rádio em Ilhéus é também falar de algum modo de política. Assim, conforme a autora, percebe-se como a imprensa modifica as relações das forças políticas locais e como os políticos e a mídia exercem influência mútua. 
d) Rádio e convergência: uma abordagem pela economia política da comunicação (2010), de Luiz Artur Ferraretto (UFRGS) e Marcelo Kischinhevsky (UERJ). 0 artigo traz questões relacionadas às novas lógicas de produção, distribuição e consumo de conteúdos radiofônicos em um ambiente de convergência midiática. A expansão do rádio rumo às plataformas digitais reconfigura as práticas comunicacionais, acelerando a concentração empresarial, mas também permitindo o surgimento de novos atores - notadamente, do setor de telecomunicações. Analisa-se, portanto, o novo lugar do rádio, indústria cultural que, conforme os autores, hesita entre as ondas eletromagnéticas e a multiplicidade de oferta de conteúdos e de canais de difusão do novo mundo digital. Estuda-se o chamado rádio comercial, discutido em quatro âmbitos: 1) tecnológico; 2) empresarial; 3) profissional e 4) de conteúdos.

e) O rádio educativo e a cibercultur@ nos processos de mobilização comunitária (2011), de Cicilia M. K. Peruzzo (UMESP). 0 estudo investiga o percurso do rádio educativo no Brasil e objetiva situar as várias faces do mesmo e refletir sobre sua passagem em diferentes momentos históricos. Pretende ainda discutir sua presença na internet e analisar a inserção do rádio educativo na cibercultur@. A pesquisa foi realizada com base em pesquisa bibliográfica e documental. Concluise que o uso educativo do rádio foi variando ao longo do tempo. Passa por um conteúdo educativo-cultural difuso, incorpora programas governamentais de ensino a distância, serve à educação de base e à difusão da "alta cultura" e à informação de interesse público, se insere em processos de ensino-aprendizagem escolar e revela uma dimensão educativa na rádio popular e comunitária.

f) A rádio comunitária como prática de cidadania comunicativa (2011), de Cristóvão Domingues de Almeida e Joel Felipe Guindani (Doutorandos UFRGS) e Valdir José Morigi (UFRGS). Os autores partem da questão: como se caracteriza a prática de cidadania comunicativa na rádio comunitária desenvolvida por agricultores Sem Terra? A resposta a esse questionamento, segundo os mesmos, passa pela definição de cidadania comunicativa enquanto estratégia de ação e de participação no espaço público. Articulando-a com a experiência observada da rádio comunitária Terra Livre FM, no Assentamento 25 de Maio, em Abelardo Luz (SC), ela é tecida por uma rede complexa de elementos que envolvem a participação, formas de 
sociabilidade e a livre manifestação dos pensamentos. Ações comunicativas que garantem a constituição de novos direitos no qual através da palavra própria realiza a mediação entre as práticas de cidadania e a participação dos sujeitos.

g) Rádio social: mapeando novas práticas internacionais sonoras (2012), de Marcelo Kischinhevsky (UERJ). 0 artigo busca mapear a emergência de novas práticas interacionais na esteira do surgimento das chamadas mídias sociais de base radiofônica, ou simplesmente, rádio social. No percurso, são discutidos os avanços nos estudos sobre recepção, interações e mediações, assim como as alterações no processo comunicacional trazidas pelas redes digitais. Apoia-se nos conceitos de radiomorfose e de remediação para caracterizar esse momento de transição em que podem ser identificadas tanto rupturas quanto continuidades na apropriação de conteúdos veiculados no âmbito da indústria da radiodifusão sonora, bem como à sua margem.

h) A produção científica sobre o rádio no Brasil: livros, artigos, dissertações e teses (1991-2001), (2004), de Doris Fagundes Haussen (PUCRS e UFRGS). 0 artigo apresenta um mapeamento dos livros, artigos, dissertações e teses sobre o rádio no Brasil, publicados no período de 1991 a 2001, identificando a sua origem e a preponderância dos temas abordados. Como base teórica de apoio é utilizada a obra de Santaella (2001) sobre os territórios da Comunicação. No levantamento efetuado encontraram-se 63 livros editados, 82 artigos e 105 teses e dissertações.

A revista Sessões do Imaginário apresenta um artigo:

a) O feminino e o pós-moderno: o contexto do hipergênero (2012), de Helen Garcez Braun (Doutoranda, PUCRS). 0 artigo busca identificar em narrativas femininas que circularam pela mídia, questões que envolvem gênero e pós-modernidade. Através de matérias que foram ao ar no rádio, contando distintas histórias de mulheres, propõe-se uma reflexão que visa perceber em que medida estas histórias estão permeadas por conceitos da pós-modernidade encontrados em autores como Michel Maffesoli, Jean Baudrillard e Gilles Lipovetsky. 


\section{Algumas considerações}

Em relação ao conteúdo, as temáticas mais abordadas nessas revistas, no período analisado (2002-2012), foram as da recepção/mediações e das narrativas radiofônicas, com quatro textos cada, seguidas das rádios comunitárias e das rádios públicas, com três textos cada. A seguir aparecem os conteúdos de política, com dois textos, e, na sequência, com um texto cada, a pesquisa sobre o rádio, a música, legislação/políticas públicas e a economia política do rádio. As categorias para análise foram sendo identificadas a partir da sua repetição nos textos. Quanto aos autores que mais publicaram nestas revistas estão Marcelo Kischinvesky, com três artigos, Cicília Peruzzzo, com dois artigos (revista Famecos), e Cida Golin também com dois (revistas In Questão e Intexto). Os demais publicaram um artigo cada.

Sobre as referências da área de rádio mais utilizadas, os autores Sonia Virginia Moreira e Marcelo Kischinhevsky foram os mais citados, seguidos por Eduardo Meditsch, Mariano Cebrián Herreros, Doris Haussen e Cicilia Peruzzo. Na sequência, aparecem os autores Nair Prata, Valci Zuculoto, Alvaro Bufarah, Gisela Castro, Ligia Maria Trigo de Souza, Gisela Ortriwano e Mario Ferraz Sampaio. Além destes, são citados vários autores, não especificamente da área de rádio, como Martin Barbero, Garcia Canclíni, Manuel Castells, Maria Immacolata Vassalo de Lopes, entre outros. É importante salientar a forte presença de autores que fazem parte do GP Rádio e Mídia Sonora da Intercom, demonstrando a relevância deste grupo no desenvolvimento de estudos sobre este veículo de comunicação.

No entanto, no que se refere às referências é interessante lembrar as observações de Martino (2014, p. 163) quando diz que "a aferição dos lugares de fala a partir das citações de outros autores permite formar um índice a partir da materialidade desse discurso na escrita dos textos", mas salienta os cuidados necessários: "a quantidade de vezes em que um autor aparece não pode ser tomada como um retrato de sua apropriação, posto que a divisão não é horizontal, isto é, pelo número de artigos em que é citado, e um autor pode ter diversas obras citadas em apenas um artigo".

Analisando-se o panorama geral das revistas dos PPGs em Comunicação da PUCRS, UNISINOS e UFRGS pode-se dizer que o rádio, ao longo dos dez anos analisados, esteve sempre presente. Nesse período, as temáticas que mais chamaram a atenção dos pesquisadores foram, como visto, as da recepção/mediações e as das narrativas e discursos radiofônicos. Por outro lado, a variedade de temas abordados indica a própria complexidade do veículo que, ao atrair o olhar dos pesquisadores mostra, também, a sua forte presença na sociedade. 
Seja na música, na política, no esporte, na economia ou na educação, tanto por ondas magnéticas quanto on-line.

0 rádio é, sem dúvida, o meio de comunicação que mais evoluiu nas últimas décadas em função das novas tecnologias. Por causa da internet, o rádio teve que se adaptar à nova realidade, renovando as linguagens existentes e ganhou mais espaço porque pode ser transmitido e ouvido por outras plataformas como celular, iPod, computadores domésticos e de mão. Por isto tudo, suscita mais pesquisas científicas e os teóricos e pesquisadores têm acompanhado essas mudanças com a atenção devida. (PRATA: MUSTAFÁ; PESSOA, 2014, p. 82).

O panorama traçado neste artigo indica, assim, a percepção de que o rádio continua a ser objeto de interesse dos pesquisadores e que os conteúdos abordados, em sua diversidade, demonstram a característica principal desta mídia que é a da proximidade com a comunidade. Os temas desenvolvidos pelos pesquisadores e identificados no levantamento realizado, como visto, apontam nessa direção.

\section{Referências}

ALMEIDA, Cristóvão Domingues de; GUINDANI, Joel Felipe e MORIGI, Valdir José. A rádio comunitária como prática de cidadania comunicativa. Revista FAMECOS, Porto Alegre, v.18, n.3, p. 959-975, 2011.

BRAUN, Helen Garcez. 0 feminino e o pós-moderno: o contexto do hipergênero. Revista Sessões do Imaginário, Porto Alegre, v. 17, n. 27, p. 58-67, 2012/1.

DEL BIANCO, Nélia; ZUCULOTO, Valci. Memória do GT de Rádio da Intercom: seis anos em defesa do rádio (1991-1996). In: Congresso Brasileiro de Ciências da Comunicação Intercom, 1996, São Paulo. Anais... São Paulo, 1996. 1 CD.

DEUS, Sandra de. Rádios Universitárias Públicas: compromisso com a sociedade e com a informação. Revista Em Questão, Porto Alegre, v.9, n. 2, p. 308-319, 2003.

FERRARETTO, Luiz Artur. Pesquisa a respeito do rádio e de outros meios sonoros no século 21: das transformações na natureza do meio e de seus congêneres aos seus usos no contexto da convergência digital. Radioleituras, Ouro Preto v. 1, n. 1, Jul./-dez. 2010 Disponível em: <http://radioleituras.worpress.com>. Acesso em 20/05/2015.

FERRARETTO, Luiz Artur. Rádio e convergência: uma abordagem pela economia política da comunicação. Revista FAMECOS, Porto Alegre, v. 17, n. 3, p:173-180, 2010.

GOLIN, Cida. 0 rádio como monitor do trânsito, termômetro e cronômetro da cidade.

Revista Em Questão, Porto Alegre, v. 16, n. especial, p. 67-78, 2010.

GOLIN, Cida. A expressão radiofônica de uma cartografia sonora: estudo da série Porto Alegre, paisagens sonoras. Revista Intexto, Porto Alegre, n. 17, p. 1-15, 2007. 
HAUSSEN, Doris Fagundes. Panorama da Pesquisa em Comunicação no Brasil. In: HAUSSEN, D.F. (org.) Mídia, Imagem e Cultura. Porto Alegre: Edipucrs, 2001.

HAUSSEN, Doris Fagundes. A produção científica sobre o rádio no Brasil: livros, artigos, dissertações e teses (1991-2001). Revista Famecos, Porto Alegre, v. 25, p. 119-126, 2004.

HAUSSEN, Doris Fagundes. Trajetória da Pesquisa em Rádio no Brasil. Palestra in Revista Rádioleituras, Ouro Preto, v. 2, n. 2, p.107-114, julho/dezembro, 2011.

HAUSSEN, Doris Fagundes. Memória dos textos sobre rádio publicados na Revista Intercom (2002-2012). In: CONGRESSO DA REDE ALCAR, 2015, Porto Alegre. Anais... Porto Alegre: UFRGS, 2015.

HERSCHMANN, Micael e KISCHINHEVSKY, Marcelo. A "geração podcasting" e os novos usos do rádio na sociedade do espetáculo e do entretenimento. Revista FAMECOS, Porto Alegre, v.1, n.37, 2008, p. 101-106.

KESKE, Humberto Ivan; PRODANOV, Cleber Cristiano e MOSER, Vinícius. "O maior espetáculo da terra" o futebol e sua capacidade de transgredi os níveis de cultura de massa. Revista Intexto, Porto Alegre, n. 26, p. 101-119, 2012.

KISCHINHEVSKY, Marcelo. Rádio social: mapeando novas práticas interacionais sonoras. Revista FAMECOS, Porto Alegre, v. 19, n. 2, p. 410-437, 2012.

LOPES, Maria Immacolata Vassalo de et al. Pensamento comunicacional brasileiro. São Paulo: Intercom, 2005.

LOPES, Débora Cristina e MUSTAFÁ, Izani. Pesquisa em rádio no Brasil: um mapeamento preliminar das teses doutorais sobre mídia sonora. Revista Matrizes, São Paulo, v. 6, n. 1, p. 189-205, 2012.

MACEDO, Silvia Mugnatto. Identidade política e programação das rádios públicas: esatudo comparativo de quatro emissoras federais. Revista Fronteiras. Estudos midiáticos. São Leopoldo, v. 14, n. 1, p: 40-51, 2012.

MARTINO, Luís Mauro Sá. Trilhas de um espaço de pesquisa: o GT Epistemologia da Comunicação da Compós. In: Revista ESPM, Comunicação, Mídia e Consumo, v. 2, n. 31, p.159-177, maio/ago. 2014.

MIOLA, Edna. Produção negociada de políticas de radiodifusão pública. A participação da sociedade no Conselho Delibertativo da Fundação Cultural Piratiní. Revista Intexto, Porto Alegre, v. 2. n.21, p. 101-119, 2009.

MOREIRA, Sonia Virginia. Rádio. In: MELO, José Marques de (Org.). 0 campo da Comunicação no Brasil. Petrópolis: Vozes, 2008.

MOREIRA, Sonia Virginia. 0 rádio no Brasil. 2 . ed. Rio de Janeiro: Mil Palavras, 2000. 
MOREIRA, Sonia Virginia; DEL BIANCO, Nélia. A pesquisa sobre o rádio no Brasil nos anos oitenta e noventa. In: LOPES, Maria Immacolata Vassalo de (Org.). Vinte anos de Ciências da Comunicação no Brasil. São Paulo: Editora Intercom, 1999. p. 85-95

NOGUEIRA, Silvia Garcia. 0 universo radiofônico de Ilhéus (BA): tênues fronteiras entre radialismo e política. Revista FAMECOS, Porto Alegre, v. 1, n. 39 p. 112-118, 2009.

PERUZZO, Cicília M. K. Rádio comunitária na internet: empoderamento social das tecnologias. Revista FAMECOS, Porto Alegre, v.1, n.30, p. 115-125, 2006

PERUZZO, Cicília M. K. O rádio educativo e a cibercultur@ nos processos de mobilização comunitária. Revista FAMECOS, Porto Alegre, v. 18, n. 3, p. 933-958, 2011.

PRATA, Nair et al. Estudos sobre o rádio na academia - o caso de Belo Horizonte. In MOREIRA, Sonia Virginia (Org.). 70 anos de radiojornalismo no Brasil. Rio de Janeiro: EdUERJ, v. 1, p. 363-376, 2011.

PRATA, Nair; MUSTAFÁ, Izani e PESSOA, Sonia Caldas. Teóricos e pesquisadores de rádio no Brasil. Revista Brasileira de História da Mídia (RBHM), São Paulo, V. 3, n.1, p. 65-82, jan.2014-jun/2014.

RONSINI, Veneza M. e ROSSATTO, Alexania. O popular e a leitura radiofônica: um estudo de recepção entre jovens camponeses. Revista Fronteiras. Estudos midiáticos. São Leopoldo, v. 10, n. 1, p. $5-13,2008$.

SANCHOTENE, Carlos; ZUCOLO, Rosana; PIRES, Juliano. No ar, a comunidade: um estudo de recepção a partir das rádios comunitárias de Santa Maria. Revista Intexto, Porto Alegre, n. 22, p. 81-98, 2010.

SILVA, Heitor da Luz. Rádio musicale concessão pública: uma reflexão a partir de duas emissoras "roqueiras". Revista Fronteiras. Estudos midiáticos. São Leopoldo, V. 10, n. 3, p. 163-172, 2008. 


\title{
Journals of the Postgraduate Programs in Communication record the research about radio
}

\begin{abstract}
This article presents an overview of articles with the theme of radio published on communications journals classified as Qualis A2 e B1 by CAPES in the period 2002-2012. It approaches, specifically, journals of the three Pós-Graduate in Communication Programs (stricto sensu), the oldest in the Rio Grande do Sul: PUCRS, UNISINOS and UFRGS. It was intented thus have a more in-depth view of the place occupied by the radio in the scientific area publications and to investigate the most discussed contents of this production, the autors who have more produced and more used references. For the choice of texts selected were those in which the title and summary indicating the link with the radio theme. They identified 20 articles and the more content covered was those related to studies of reception/mediations and radio narratives.
\end{abstract}

\section{Keywords}

Radio. Communications journals. Rio Grande do Sul.

Recebido em 08/09/2015

Aceito em 11/12/2015 